\title{
Successful ecosystem-based management of Antarctic krill should address uncertainties in krill recruitment, behaviour and ecological adaptation
}

\author{
Bettina Meyer (10) 1,2,3凶 , Angus Atkinson ${ }^{4}$, Kim S. Bernard ${ }^{5}$, \\ Andrew S. Brierley (10 ${ }^{6}$, Ryan Driscoll (1) ${ }^{1}$, Simeon L. Hill (1) ${ }^{7}$, Enrique Marschoff ${ }^{8}$, \\ Dale Maschette (10) 9,10, Frances A. Perry (1) ${ }^{4}$, Christian S. Reiss ${ }^{11}$, \\ Emilce Rombolá (10) ${ }^{8}$, Geraint A. Tarling (1) ${ }^{7}$, Sally E. Thorpe (i) ${ }^{7}$, \\ Philip N. Trathan7, Guoping Zhu (1D) ${ }^{12,13}$ \& So Kawaguchi (i) ${ }^{10}$
}

Antarctic krill, Euphausia superba, supports a valuable commercial fishery in the Southwest Atlantic, which holds the highest krill densities and is warming rapidly. The krill catch is increasing, is concentrated in a small area, and has shifted seasonally from summer to autumn/winter. The fishery is managed by the Commission for the Conservation of Antarctic Marine Living Resources, with the main goal of safeguarding the large populations of krilldependent predators. Here we show that, because of the restricted distribution of successfully spawning krill and high inter-annual variability in their biomass, the risk of direct fishery impacts on the krill stock itself might be higher than previously thought. We show how management benefits could be achieved by incorporating uncertainty surrounding key aspects of krill ecology into management decisions, and how knowledge can be improved in these key areas. This improved information may be supplied, in part, by the fishery itself.

\footnotetext{
A ntarctic krill (Euphausia superba, hereafter referred as krill) is a key dietary item for vertebrate predators, such as whales, seals, seabirds, and fish, as well as for invertebrates ${ }^{1}$. At between 300 and 500 million tonnes $^{2}$ its biomass is the largest of any multicellular wild animal species on the planet ${ }^{3}$. Krill is an important grazer of autotrophic and heterotrophic
}

\footnotetext{
${ }^{1}$ Alfred Wegener Institute Helmholtz Centre for Polar und Marine Research, Am Handelshafen 12, Bremerhaven, Germany. ${ }^{2}$ Institute for Chemistry and Biology of the Marine Environment, University of Oldenburg, Carl-von-Ossietzky-Straße 9-11, 26111 Oldenburg, Germany. ${ }^{3}$ Helmholtz Institute for Functional Marine Biodiversity at the University of Oldenburg (HIFMB), Ammerländer Heerstrasse 231, Oldenburg 26129, Germany. ${ }^{4}$ Plymouth Marine Laboratory, Prospect Place, The Hoe, Plymouth PL1 3DH, UK. ${ }^{5}$ College of Earth, Ocean, and Atmospheric Sciences, Oregon State University, 104 CEOAS Admin Bldg., Corvallis, OR 97330, USA. ${ }^{6}$ Scottish Oceans Institute, School of Biology, Gatty Marine Laboratory, University of St Andrews, St Andrews, Fife KY16 9TS, UK. ${ }^{7}$ British Antarctic Survey, Natural Environment Research Council, High Cross, Madingley Rd, Cambridge CB3 OET, UK. ${ }^{8}$ Instituto Antártico Argentino, Dirección Nacional del Antartico, 25 de Mayo 1143, San Martín, Buenos Aires, Argentina. ${ }^{9}$ Fisheries and Aquaculture Centre, Institute for Marine and Antarctic Studies, University of Tasmania, Hobart, Tasmania 7001, Australia. ${ }^{10}$ Australian Antarctic Division, Kingston, Tasmania 7050, Australia. ${ }^{11}$ National Oceanic and Atmospheric Administration, Antarctic Ecosystem Research Division, Southwest Fisheries Science Center, La Jolla, CA 92037, USA. ${ }^{12}$ College of Marine Sciences, Shanghai Ocean University, 999 Huchenghuan Road, Pudong New District, 201306 Shanghai, China. ${ }^{13}$ Center for Polar Research,

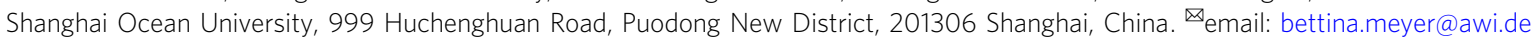


plankton ${ }^{3,4}$ and has a key role in biogeochemical cycles, such as carbon export ${ }^{5}$ and iron-recycling 6 .

The Southwest (SW) Atlantic sector of the Southern Ocean (SO), where $70 \%$ of the krill population resides ${ }^{2}$, is the main focus of the modern krill fishery ${ }^{8,9}$, which is managed by the Commission for the Conservation of Antarctic Marine Living Resources (CCAMLR). The SW Atlantic sector is also amongst the global regions most affected by climate change ${ }^{10,11}$. The krill fishery has existed for 50 years, and over this time has seen changes in geographic focus, fleet nationality composition, and the technologies used to locate and catch krill. In the past two decades, the krill catch has been taken mainly from the waters surrounding the Antarctic Peninsula and South Shetland Islands (CCAMLR Subarea 48.1), the South Orkney Islands (Subarea 48.2), and South Georgia (Subarea 48.3) (Fig. 1) ${ }^{9}$. Historically, the fishery operated mainly in summer, but is now focused in autumn/winter (Fig. 2) as fishers increasingly target krill that are rich in high-profit omega-3 lipids ${ }^{9}$ that have accumulated over summer. This temporal shift has been facilitated by decreasing sea ice extent that has enabled greater access to a wider choice of fishing locations, especially in the southern fishing grounds ${ }^{12}$.

In this paper, we review krill population dynamics and the present state of krill management, with a focus on how the latest knowledge, and gaps in that knowledge, may impact the effectiveness of present fishery management regulations. We highlight the needs in the following areas of research:

- mechanisms of krill recruitment and recruitment measurement,

- spawning hotspots and larval advection,

- drivers of seasonal distribution and migration and the overwintering spawning stock,

- potential implications of the size of the successful spawning stock being smaller than presently assumed,
- differences in estimates of population trends,

- climate change implications for krill dynamics.

To address these needs, we then suggest how new data, techniques and collaborative efforts between researchers and fishers may be used to acquire the knowledge needed to manage the krill fishery for the future.

This paper is the first output of the Krill Action Group, established in 2018, under the umbrella of the Scientific Committee of Antarctic Research (SCAR). One of the key aims of the SCAR Krill Action Group (SKAG) is to inform CCAMLR about up-to-date scientific knowledge on krill that is relevant for the management of the krill fishery.

\section{Krill fishery-management by CCAMLR}

CCAMLR was established in 1982 in direct response to the exploitation of krill and the potential risks of this exploitation to the wider SO ecosystem. Today, CCAMLR consists of 26 Members and 10 Acceding States. The Commission implements management directives called conservation measures (CMs), which are adopted by consensus. The CMs that regulate the operation of the krill fishery concern precautionary catch limits, gear restrictions, data reporting, notification of intent to fish, minimization of incidental mortality, observer deployment, and exploratory fisheries ${ }^{8}$.

In 1991, CCAMLR agreed to set the first catch limit for krill for the entirety of Area 48 (i.e., Subarea 48.1 to 48.6 ) (Fig. 1) at 1.5 million tonnes per fishing season (December to November) based on the outcome of the SCAR BIOMASS surveys in $1981^{8,13}$ and a krill yield model ${ }^{14}$. Together these determined a catch limit consistent with the complementary objectives of preserving the spawning stock biomass (SSB) and reserving a portion of krill production to account for the needs of krill predators. In agreeing to a catch limit for this large area (Area 48 is 12.619 million $\mathrm{km}^{2}$ ), CCAMLR also agreed that if the total catch in Subareas 48.1, 48.2,

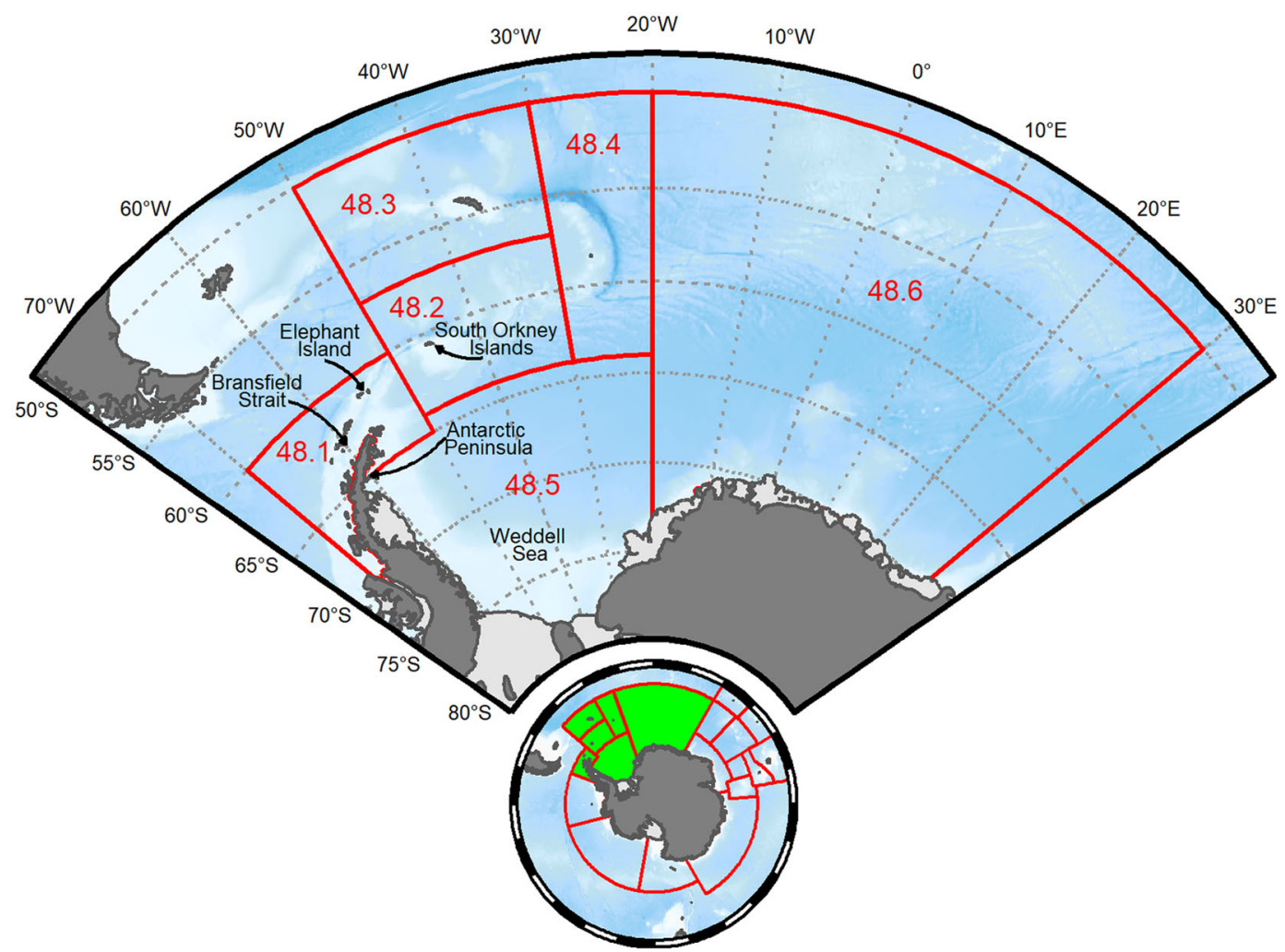

Fig. 1 Map of the study region. Convention area 48 (green area) of the Commission for the Conservation of Antarctic Marine Living Resources (CCAMLR) and its Subareas. 
a

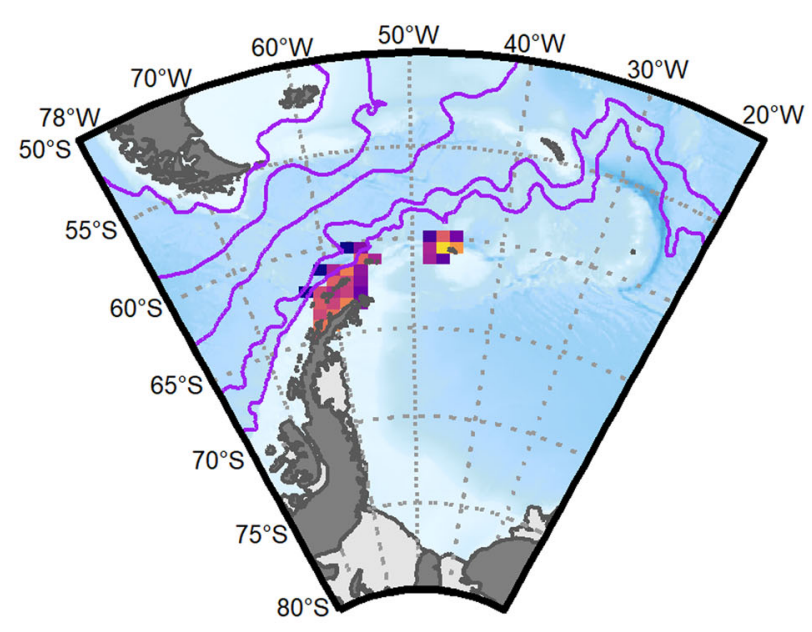

C

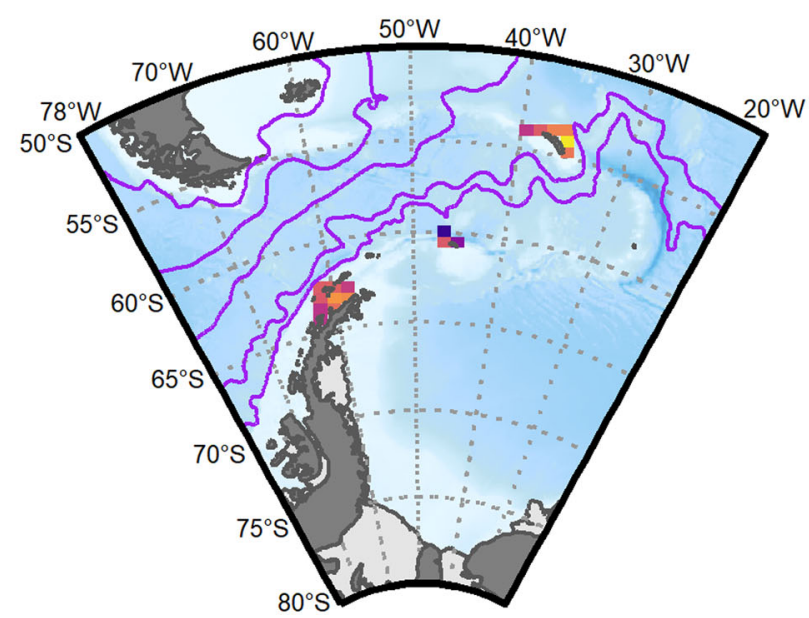

b
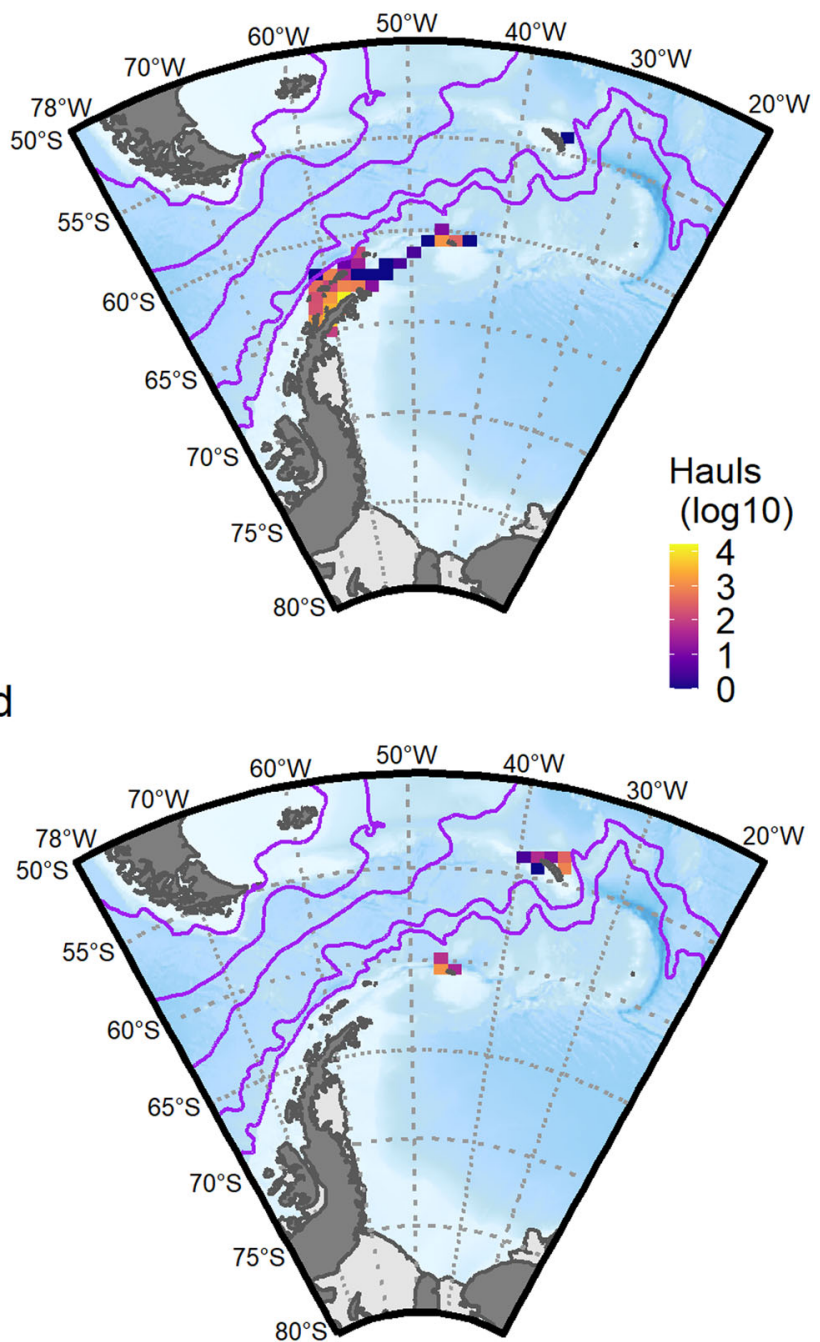

Fig. 2 Total number of krill fishing hauls in CCAMLR Area 48 ( $\log _{10}$ hauls) in CCAMLR fishing seasons 2014/15-2017/18. a Austral summer (December-February), b Autumn (March-May), c Winter (June-August), d Spring (September-December). The mean positions of the main fronts of the Antarctic Circumpolar Current are marked in purple 100,101 . Bathymetry shading from $250 \mathrm{~m}$ to $4500 \mathrm{~m}$.

48.3 and $48.4\left(639,317,856,086,1,029,732\right.$ and $944,953 \mathrm{~km}^{2}$, respectively) exceeded 620,000 tonnes then catch limits would have to be set at a finer spatial scale, such as by Subarea, to restrict the potential for all of the 1.5 million tonne catch limit being taken from a small part of the overall area. This 620,000 tonne "trigger level" for setting finer scale catch limits was based on the sum of the maximum pre-1991 annual catches in each of the four subareas $(48.1-48.4)^{8,15}$. Since 1991, when the Area 48 total catch limit was first set, it has been updated to 5.6 million tonnes, following an international biomass survey in $2000^{15}$. The original trigger level has, however, been retained, but with the stipulation that catch limits should be set at smaller spatial scales, such as set of proposed "small scale management units" (SSMUs) ${ }^{15,16}$. CCAMLR has also clarified that both the catch limit and the trigger level apply to Subareas 48.1-48.4.

In 2009, CCAMLR further agreed to subdivide the trigger level spatially, establishing interim catch limits for each of Subareas 48.1-48.4 (Fig. 1, Table $1^{15}$ ). This measure is intended to provide more time for CCAMLR to progress to managing at smaller scales, and was adopted in response to model-based evidence that spatial concentration of the trigger level could negatively impact
Table 1 Historical (pre-1991) maximum annual catch and present catch limit in tonnes wet mass for each of Subareas 48.1 to 48.4 where the krill fishery currently operates ${ }^{14}$.

\begin{tabular}{llll} 
Subarea & $\begin{array}{l}\text { Historical } \\
\text { maximum catch } \\
\text { taken }^{\mathbf{a}}\end{array}$ & $\begin{array}{l}\text { Interim catch limit } \\
\text { (established in } \\
\mathbf{2 0 0 9 )}^{\mathbf{b}}\end{array}$ & $\begin{array}{l}\text { 2019 catch } \\
\text { (CCAMLR 2018/ } \\
\text { 2019) }^{\mathbf{c}}\end{array}$ \\
\hline 48.1 & 105,554 & 155,000 & $155,907^{\star}$ \\
48.2 & 258,596 & 279,000 & 162,416 \\
48.3 & 312,134 & 279,000 & 63,599 \\
48.4 & 19 & 93,000 & 0
\end{tabular}

aData obtained from www.ccamlr.org/node/92869.

bThese Subarea-scale interim catch limits are subject to a total catch limit across all four Subareas of 620,000 tonnes (i.e., the 'trigger level').

'Data obtained from the SC-CCAMLR Report $2019^{24}$

* Set catch limit is reached.

krill predators ${ }^{15,17}$. The measure does, however, allow catches in three of the four subareas to be higher than the historical maxima used to set the trigger level (Table 1). 
a

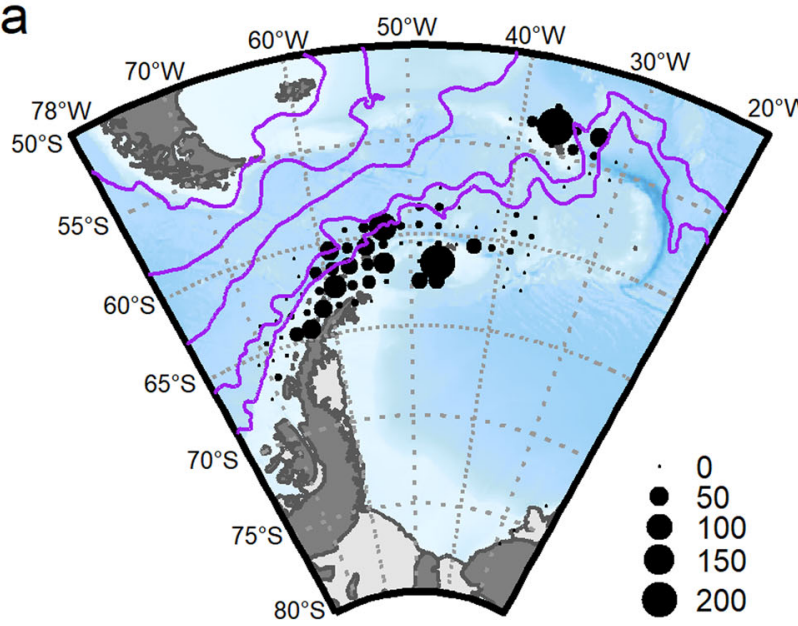

b

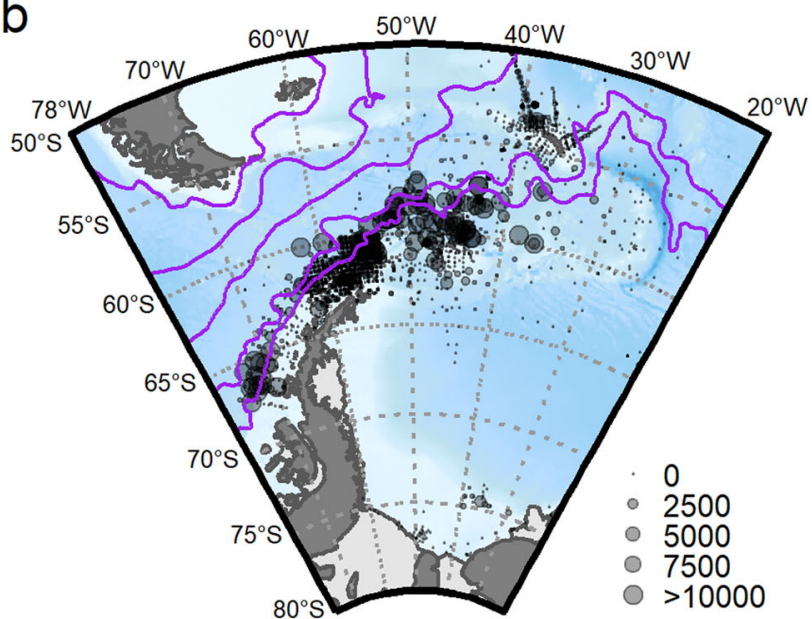

C
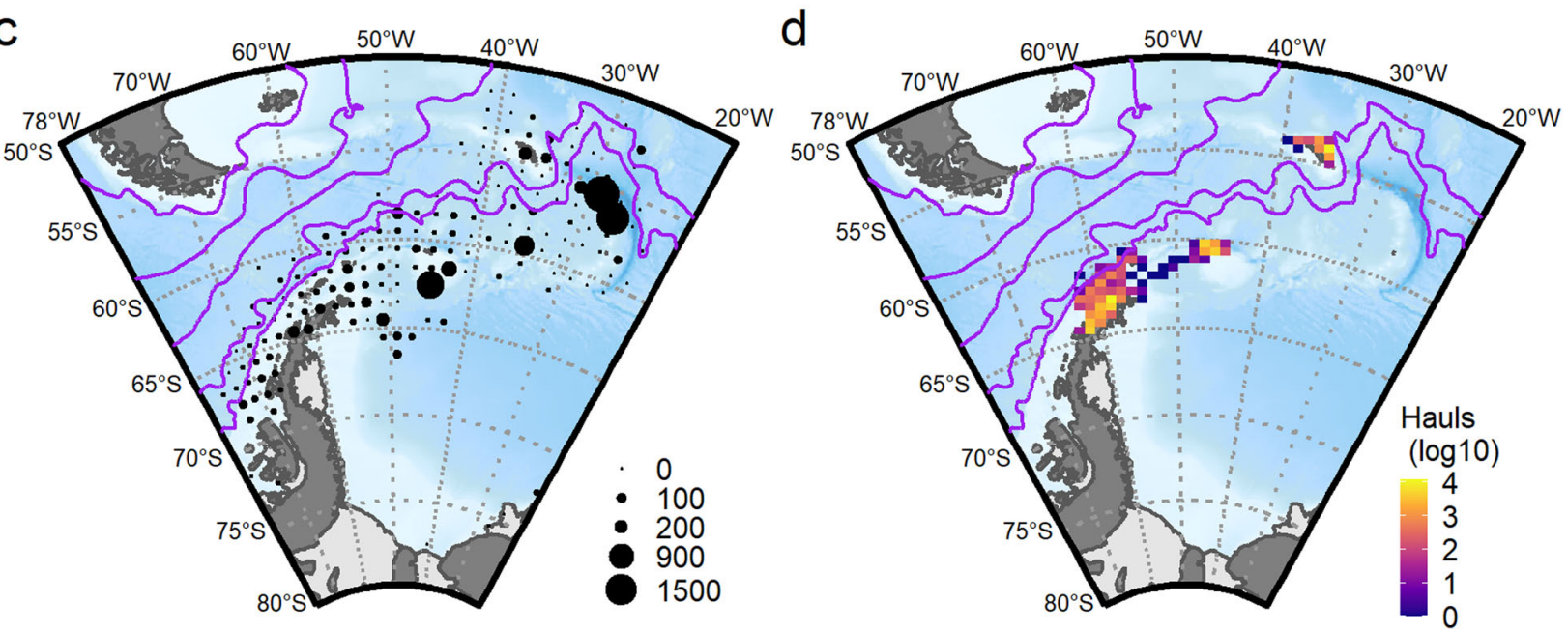

Fig. 3 Abundance and distribution of Antarctic krill, Euphausia superba (no. ind. $\mathbf{m}^{\mathbf{2}}$ ) in relation to krill fishing effort. a Adult female krill in early season (October to December) from KRILLBASE, b larval krill (Calyptopis 1 to Furcilia 6 combined) from KRILLBASE 1976-2014, adapted from Perry et al. ${ }^{42}$. c Adult krill (females and males combined) in late season (January to April), and $\mathbf{d}$ fishing effort in all austral seasons from 2015 to 2018 . The locations of the main oceanographic fronts are marked in purple 100,101 . Bathymetry shading from 250 to $4500 \mathrm{~m}$.

The annual krill catch in the SW Atlantic sector has been increasing steadily since 2010 and, in the 2019 fishing season (December 2018 to November 2019) it reached 390,195 tonnes. In fact, the interim catch limit has been reached regularly in recent years (2010 and 2013 through to 2019) in Subarea 48.1, the Antarctic Peninsula (Table 1) ${ }^{15}$, resulting in the closure of this Subarea for the remainder of the season. Catches in Subarea 48.1 are now more concentrated in space and time than ever before ${ }^{8,9,18}$. The demand for krill will likely increase, driven by at least two industries. First the increasing production of carnivorous fish through aquaculture and the subsequent increase in demand for fish meals and marine byproducts. Second, the increasing demand for high value pharma- and nutraceutical products from krill oil and krill meals. A recent publication by Nicol and Foster $^{8}$ gives a comprehensive overview of the industrial demands for krill and of the development of catch techniques from their beginnings in the 1970's through present.

Much of the discussion of krill fisheries management in CCAMLR has been focused on the protection of land-breeding krill predators and on fishing operations. The former is consistent with CCAMLR's mandate to protect populations that are dependent upon krill. Indeed, long-term observations of colonies of krill-feeding penguins around the South Shetland Islands have shown that in some years fishing can cause detectable negative impacts on these colonies ${ }^{19}$.

In recent times, there has been relatively little discussion of the risks posed by the fishery to the krill population itself. This lack of attention reflects a view that catches up to the trigger level could not have a measurable impact on the krill population because they represent only a small fraction of overall biomass (ca. 1\%). However, this view is challenged by the high levels of variability observed in available indices of krill abundance, which typically span two to three orders of magnitude ${ }^{15,20,21}$ and in the increasing spatial focus of the fishery (Fig. $3 \mathrm{~d})^{9}$, which could result in substantial local impacts.

Discussions at the Third International Symposium on Krill in $2017^{22}$ and at the Scientific Committee meeting of CCAMLR in the same year ${ }^{23}$ led to the establishment of a Krill Action Group under the umbrella of the Scientific Committee of Antarctic Research (SCAR) in 2018. In 2019, CCAMLR agreed to develop a revised management approach for krill ${ }^{24}$. A key aim of the SCAR Krill Action Group (SKAG) is to inform that process. This paper highlights areas that we, SKAG, believe warrant most pressing attention for the management of the krill fishery. 


\section{Krill ecology: new data, present theories, and knowledge gaps}

Mechanisms of krill recruitment and recruitment measurement. Understanding the distribution and abundance of new recruits and the mechanisms that determine a successful recruitment is critical information in fisheries management. Krill spawn in late austral spring (December) until late summer (March), with an inter-annual variation of $\sim 4$ weeks at the beginning or end of the spawning season at any given location ${ }^{25}$. Eggs sink to deep water before hatching, then early stage larvae ascend toward the surface, and continue their development into juveniles through winter $^{26}$. Recruitment for krill is defined as the surviving juveniles joining the population the following spring ${ }^{26}$. For successful reproduction, female krill need food of sufficient quality (e.g., pelagic diatoms) and quantity to facilitate egg production ${ }^{3,27}$. During development, the first feeding larval stage must find sufficient food within ca. 10 days of reaching the surface layers to avoid starvation ${ }^{28}$. For successful recruitment, larvae must be transported by the currents to areas where they can overwinter successfully and where the newly recruited juveniles are in proximity to productive regions in spring for rapid growth ${ }^{29}$.

Krill recruitment fluctuates greatly between years, with typically only one or two strong recruitments occurring per decade. Accordingly, the biomass of krill in some locations also varies greatly between years, with biomass in "poor krill years" being $<10 \%$ of the long-term regional average e.g. at Elephant Island and South Georgia $15,20,21$. While the exact dynamics vary between regions, there is some evidence of cyclicity of interconnections between regions ${ }^{30}$ and of cyclicity, especially in the Western Antarctic Peninsula region ${ }^{31-33}$ and at South Georgia $^{21,34}$. However, there is little evidence of a stock-recruit relationship, and all observed "poor krill years" have been followed by years of average or high krill biomass. The proportion of juvenile krill (typically $<35 \mathrm{~mm}$ in length, but with geographic variability) in the population provides a measure of recruitment success, which is a key factor in krill population models. However, while recruitment as a proportion of the total stock size shows inter-annual, in some cases cyclical, variability, the absolute density of recruits measured during surveys is not sufficient to support the long-term average of the measured density of the adult population ${ }^{35}$. The apparent mismatch between field observations of recruit numbers and expectations from population dynamics theory needs to be reconciled in order to quantify the relationship between krill recruitment indices and absolute recruitment.

Environmental conditions correlated with enhanced recruitment (e.g., average ice winters in the West Antarctic Peninsula or heavy ice winters near the tip of the Antarctic Peninsula), along with negative southern annual mode (SAM) and the cool phase of the El Niño Southern Oscillation (ENSO), are thought to provide good conditions for feeding and/or shelter from predators throughout the first year of life for larvae, thus boosting survival of the new recruits ${ }^{32,33,36-38}$. Recent modeling studies suggest that the seasonal location of sea ice is the main limiting factor for successful larval recruitment ${ }^{39,40}$. Early seasonal sea ice formation and extensive coverage in late autumn and during winter is hypothesized to promote survival by spatially separating developing larvae from the adult population, reducing ontogenetic competition for food and minimizing cannibalistic predation on larval krill by post-larvae $e^{40}$. While such hypotheses offer potential explanations of the relationship between recruitment and sea ice conditions, the mechanisms behind them are still poorly understood.

Spawning hotspots and larval advection. In the SW Atlantic, spawning and early larval development takes place in association with oceanic frontal zones ${ }^{41}$, at the Weddell-Scotia Confluence and at the shelf break ${ }^{42}$. This suggests that off-shelf migration and subsequent spawning off-shelf is a crucial component of the life cycle, notwithstanding the fact that successful reproduction can occur in some shelf areas ${ }^{43}$. A compilation of krill abundance and distribution data adapted from Perry et al. ${ }^{42}$ demonstrates that, in early season (October to December), female krill are located in shelf-slope areas along the western Antarctic Peninsula to the South Orkney Islands (Fig. 3a). In late season (January to April), larval krill appear along shelf-slope and adjacent areas in the same region (Fig. 3b), while adult krill (both males and females) are broadly distributed on and off shelf (Fig. 3c). This suggests one key result in population dynamic and management contexts: that only a small, spatially restricted portion of the adult biomass (possibly as little as 14\%) spawns successfully, and these krill are potentially responsible for replenishing the entire krill population over the whole SW Atlantic sector. The question as to whether a small portion of the population can sustainably replenish the entire Area 48 krill population remains a major knowledge gap. Spawning areas further south, including in the Weddell Sea and Bellingshausen Sea are often suggested as source areas, and may contribute to the population in the region, but data are sparse ${ }^{44}$. Quantifying the contribution of these seas to overall recruitment is a priority for future research.

The risk of fishing on the potential spawning stock in spring and summer is presently slight because the fishery has shifted its main period of activity from mid-summer toward autumn and winter $^{8,9}$. Nonetheless protection of spawning areas, using measures, such as seasonal closures, may be necessary to ensure that the numerically-limited spawning stock does not decrease below critical levels ${ }^{45}$ in the event of future changes in catch distribution. Such measures may be relatively easy to agree to under present circumstances where there is no immediate conflict with the operation of the fishery.

The Antarctic Peninsula is an important spawning ground and recruitment there fluctuates nearly synchronously across its large geographic area ${ }^{31,46}$. However, production of larvae along the Peninsula is uncorrelated between regions ${ }^{47}$, with different temporal patterns being evident at the northern and western Antarctic Peninsula (NAP and WAP, respectively). Recent patterns of recruitment are correlated solely with larval production from the WAP, suggesting that krill production is presently being driven by upstream sources. High numbers of early larval krill stages (calyptopis) have been observed off Marguerite Bay half-way down the WAP, as well as near the tip of the NAP48. Trajectories of near-surface satellite-tracked, ocean drifters ${ }^{49}$ indicate that larvae found along the Antarctic Peninsula and Scotia Arc ${ }^{42,47}$ may come from both local and more remote locations along the Antarctic Peninsula itself (Fig. 4).

In addition to the potential influx of larvae from the Antarctic Peninsula, there is interest in understanding the relative contribution of Weddell Sea larvae to recruitment through advection and migration, at the NAP, Bransfield Strait, Elephant Island, and the South Orkney Islands. Considerable numbers of krill larvae and postlarvae can be associated with the sea ice edge in the Weddell Sea, and models have suggested that production in the northeastern Antarctic Peninsula region (northwestern Weddell Sea) could be an important source of larvae for the Scotia Sea population 29,39 .

Answering the question of whether the biomass of the successful spawning stock is smaller than that of the entire spawning stock is of critical importance to fishery management. This requires identification of the key regions of krill larvae production, and quantification of the flux of larvae among those regions, to areas of high krill recruitment and to areas of interest to the fishery. 

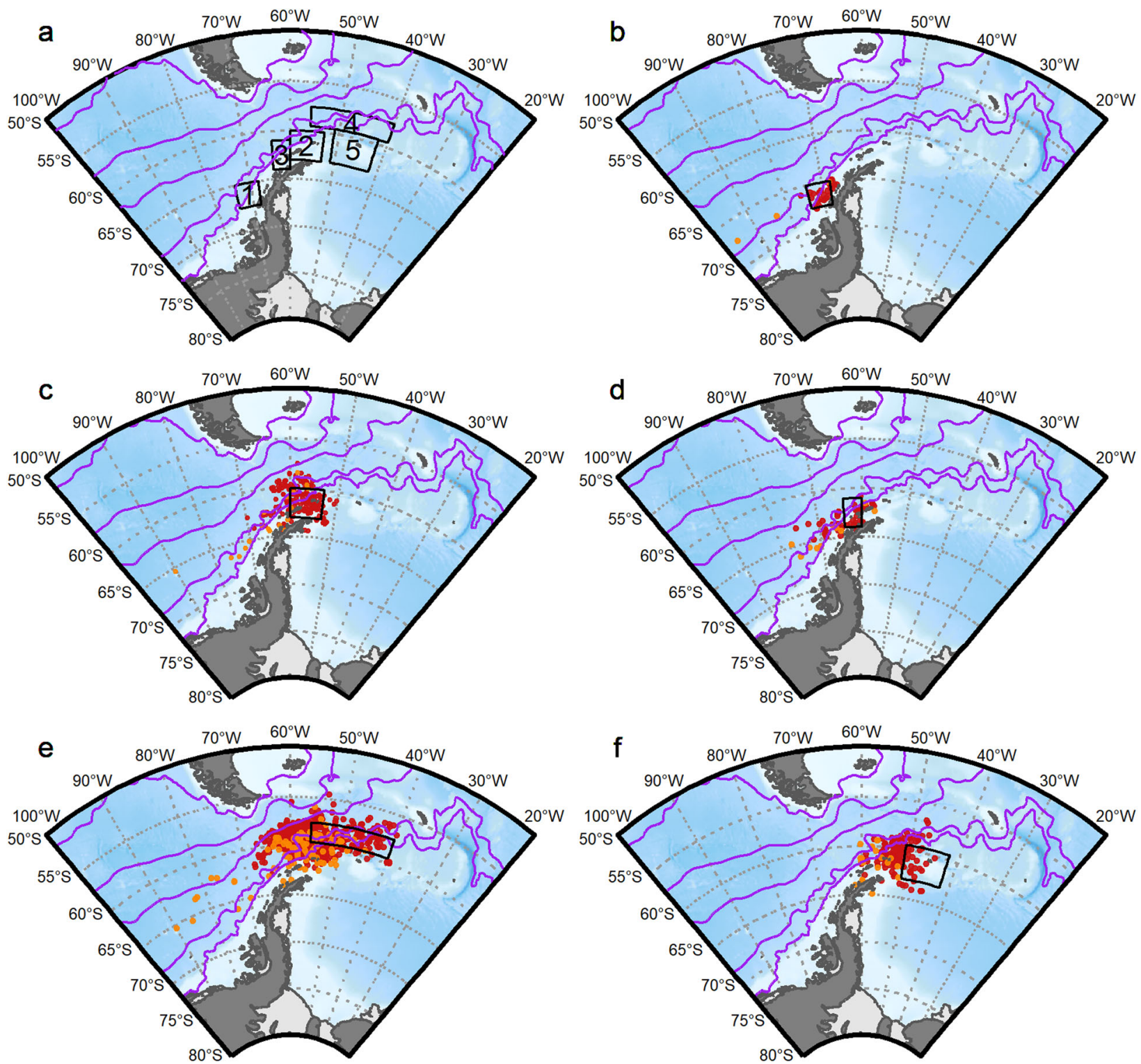

Fig. 4 Potential source regions for larval krill. Trajectories of 444 near-surface satellite-tracked drifting buoys 49 , drogued at $15 \mathrm{~m}$ depth, were used to determine the possible origins of larval krill distribution. Larval krill distribution (Fig. 3b) was divided into five areas (a) and drifters passing through each larval area were identified (b-f). Positions of those drifters at 30 (red dots) and 120 days (orange dots) before entering and exiting each larval area are plotted, corresponding to approximate development times for larval stages Calyptopis 1 and Furcilia 6 at $0^{\circ} \mathrm{C}^{102}$. The number ( $n$ ) of drifters that passed through each larval area is as follows: $\mathbf{b} n=24, \mathbf{c} n=144, \mathbf{d} n=36, \mathbf{e} n=338, \mathbf{f} n=85$; note some drifters passed through multiple larval areas. The drifters were deployed between 1989 and 2019, with 60\% of deployments made during austral summer (December-February). The main fronts of the Antarctic Circumpolar Current are marked in purple ${ }^{100,101}$. Bathymetry shading from 250 to $4500 \mathrm{~m}$.

Drivers of seasonal krill migration and overwintering spawning stock. A major part of krill life history is thought to be the seasonal offshore-onshore migration of the spawning stock along the Antarctic Peninsula $26,50,51$. In this region in spring, at the onset of the spawning season, krill show a distinct spatial separation by maturity stage, although some overlap is evident (Fig. 5) ${ }^{42,50}$. In general, smaller, immature krill inhabit coastal waters, while the distribution of large, gravid, and spawning adults extends to the continental slope in oceanic waters. This spatial segregation of developmental stages in summer may be explained by active offshore migration of adults ${ }^{50}$, such that spawned eggs encounter waters sufficiently deep for successful development $^{52}$.

In autumn and winter, the distribution of the adult population shifts from its predominately off-shelf summer distribution to on- shelf, and moves deeper in the water column ${ }^{53}$. While there are several possible explanations for this, including retention near spawning grounds ${ }^{54}$, shifts in food distribution, and behavioral response to changes in predator distributions, the exact reason is unclear. Importantly, the present fishing effort overlaps the winter krill distribution, which is more concentrated and deeper in autumn and winter ${ }^{55}$. Other hypotheses hold that seasonal changes in krill distribution may be related to predator-prey interactions ${ }^{56}$. For example, seasonal changes in predator demand might result in differential consumption of mature krill ${ }^{57}$ nearshore during the summer, skewing spatial patterns of krill length composition determined from diet samples. The recovery of cetacean populations in Subareas 48.1 and $48.2^{58-61}$ may have seasonal impacts on krill biomass, while the behavioral response by krill to changing levels of predation could affect krill 


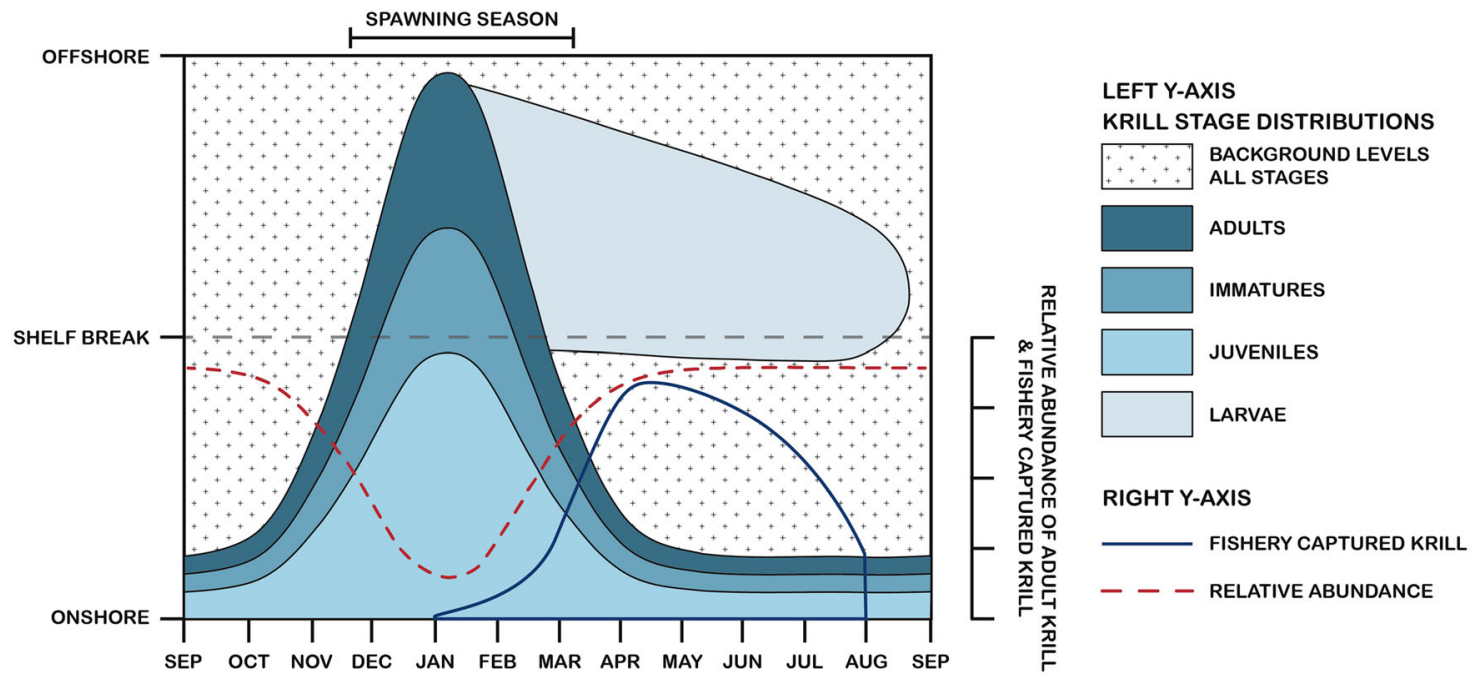

Fig. 5 Schematic of seasonal spatial and temporal distribution of Antarctic krill life-stages in relation to fishing activity. The $y$-axis (left) shows the distance of life stages from land across seasons ${ }^{26}$, whereas the $x$-axis (right) shows the relative abundance of post-larval krill in relation to fishery captured krill. Superimposed onto background levels of all krill stages across time and space are bulk movements of the adult population from inshore-shelf regions during winter to shelf-beak and off-shelf regions during summer. The dashed red line indicates the relative abundances of post-larval krill within the present-day fishing region. The blue shaded region indicates captured krill during the present-day krill fishing season and is based on 2017 catch data from CCAMLR (note that fishing gear optimally retains immature and adult krill) 103

population structure. In winter, the sea-ice environment provides krill with some refuge from air-breathing predators, and migration of baleen whales to lower latitudes reduces predation pressure. It is important to note that these predator-prey hypotheses, while plausible, remain untested.

A more complete understanding of the overwintering location of the krill population, and how the distribution of fishing effort potentially affects spawning in the following year, is essential for effective management of the new autumn/winter fishery.

Potential implications of the contributing spawning stock being smaller than presently assumed. CCAMLR's krill yield model ${ }^{14}$, which is used to establish catch limits, assumes that the impact of krill fishing is distributed evenly across the spawning stock and that all parts of the spawning stock contribute equally to the next generation. Two factors may impact the validity of these assumptions: (1) the successful spawning stock (the biomass of reproductively mature krill that are responsible for recruitment to the adult population) is much smaller than the total adult biomass (i.e. the biomass of all krill that have reached reproductive maturity) (see Spawning hotspots and larval advection); and (2) the fishing mortality disproportionately affects the successful spawning stock. The evidence supporting the first factor is provided by long-term krill abundance and distribution data (1926 to 1939 and 1976 to 2004), which suggest that mean krill density over shelf-slope areas (water depth $<2000 \mathrm{~m}$ ) is only 1.7 times that over deep oceanic waters ${ }^{62,63}$. However, because of the 10 -fold greater habitat area of the deep ocean, this equates to $86 \%$ of the total krill population inhabiting waters deeper than 2000 $\mathrm{m}^{63,64}$. If we assume, according to the krill distribution pattern shown in Fig. 3, that viable reproduction only occurs within the shelf-slope areas ${ }^{43}$, then the successful spawning stock is just $14 \%$ of the population, but see early discussion for caveats around this assumption.

At present, there is no explicit prohibition of fishing on the spawning stock, suggesting that the importance of the second factor, disproportionate fishing on the successful spawning stock cannot be discounted. Box 1 illustrates how these two factors could potentially cause fishery impacts on the contributing spawning stock to exceed the safe limits implied by CCAMLR's process for setting catch limits.

Differences in estimates of krill population trends. While the krill habitat in the SW Atlantic sector has clearly undergone rapid climatic change, with warming $\left(0.74{ }^{\circ} \mathrm{C}\right)^{65}$ and shorter sea ice duration ( 3 month $)^{66}$ over the last century, there has been a hiatus in both of these trends over the last few decades ${ }^{67,68}$ despite an increasingly positive SAM anomaly since the $1950 \mathrm{~s}^{69-71}$. Concomitantly, there is considerable debate and uncertainty over trends in krill population size in the SW Atlantic sector during the last half-century. In recent years, there have been two largescale Area 48-level krill biomass surveys (ca. 2 million $\mathrm{km}^{2}$ ), conducted in 2000 and 2019, both of which resulted in similar biomass estimates ( $\sim 60$ million tonnes) ${ }^{72}$. Variability in the krill stock size has been studied using a variety of proxy indices at regional spatial scales. Some analyses of the data from these regional studies suggest the absence of directional change $e^{21,35,73}$. Other studies suggest a decline in krill within the SW Atlantic sector and/or shifts in distributional range or mean size $37,38,73-78$. There is no signal of directional change that is consistent across all of the indices (biomass, numerical density, size, and occurrence in predator diets), spatial scales $\left(<10^{4}\right.$ to $\left.>10^{6} \mathrm{~km}^{2}\right)$, locations $\left(54^{\circ} \mathrm{S}\right.$ to $\left.64^{\circ} \mathrm{S}\right)$ or temporal scales (11 to 80 years). One interpretation is that a general, long-term trend at the larger scale is masked by high levels of interannual variability and nonlinearity between indices and scales ${ }^{38,79,80}$. This interpretation is consistent with strong evidence that krill is sensitive to climatic modes such as the SAM and the $\mathrm{ENSO}^{33,37}$ and that climatic conditions in the SW Atlantic have become increasingly unfavorable for recruitment ${ }^{38}$. An alternative interpretation is that the average density of the population is stable amid rapid climate change $\mathrm{e}^{73,81}$.

Understanding the past dynamics of krill is necessary for reliable projections of future scenarios. Therefore, there is a clear need to better characterize the uncertainties associated with the various indices and to develop a scientific consensus on interpretation. 


\section{Box 1 | Potential implications of fishing on the succesful spawning stock}

Two levels of catch limit have been established by CCAMLR. The first is the catch limit for Subareas 48.1-48.4 (Fig. 1), which is 5.6 million tonnes (9.3\% of the estimated spawning stock biomass in 2000) and the second is the interim catch limit for each of the four Subareas (Fig. 1 and Table 1$)^{15}$. The process for setting the 5.6 million tonne catch limit assumes that the entire adult population contributes equally to the next generation. However, long-term abundance and distribution data suggests that the successful spawning stock is restricted to shelf slope areas (Fig. 3a), where fishing takes place. Here we illustrate the potential impact of fishing when the successful spawning stock represents different percentages of the total biomass, which fluctuates between years 20,34 .

The data for the illustration come from US-AMLR surveys of krill biomass at the tip of the Antarctic Peninsula conducted between 1996 and 2011 (around the South Shetland-, Elephant-, and Joinville Island areas). This survey area is $125000 \mathrm{~km}^{2}$, that is ca. $20 \%$ of Subarea $48.1^{45}$.

The illustration in Figure Box 1 concerns a hypothetical spawning stock biomass (SSB) at the scale of Subarea $48.1\left(658738.6 \mathrm{~km}{ }^{2}\right.$, Fig. 1) which is the product of estimated biomass density and area, an illustrative safe exploitation rate (ER) of $9.3 \% 15$, and three scenarios in which the successful spawning stock is the sole target of the fishery but constitutes different fractions of the overall SSB (100,50, and 20\%). The figure shows the exploitation rate on the successful spawning stock for each of these scenarios based on the interim catch limit of 155,000 tonnes.
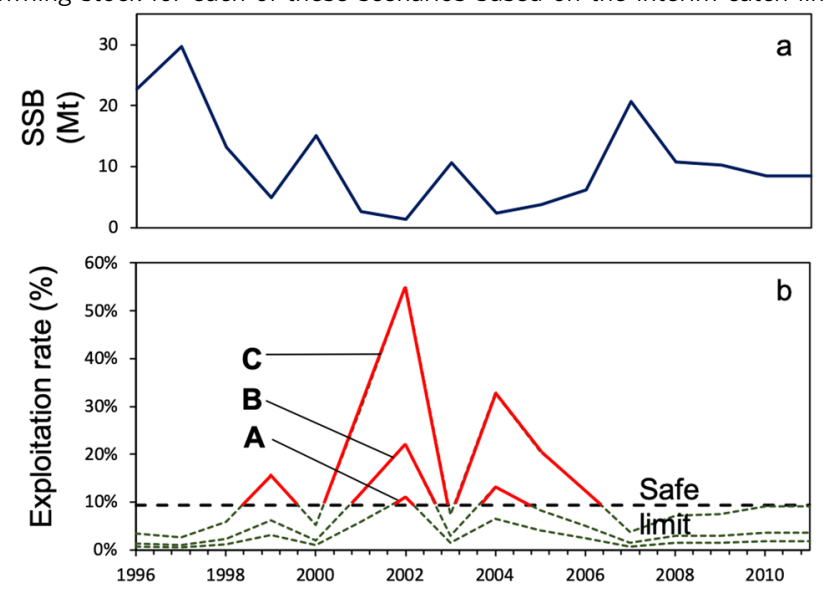

Figure Box 1 Year-to-year variation in hypothetical krill spawning stock biomass (SSB, top panel) in Subarea 48.1 and potential exploitation rates (ERs, bottom panel) on the successful spawning stock. Dashed colored lines show ERs on the successful spawners resulting from fishing the interim catch limit of 155,000 tonnes under three scenarios; A: all adult krill are successful spawners, B: 50\% of adult krill are contributing spawners, and C: only $20 \%$ of the adult krill are successful spawners. The dashed black line depicts an illustrative safe ER of $9.3 \%$ of biomass in each year. The CCAMLR catch limit for Subareas $48.1-48.4$ is $9.3 \%$ of estimated biomass in the year 2000 and is intended to be consistent with the twin objectives of preserving the spawning stock biomass and reserving a portion of krill production to account for the needs of krill predators ${ }^{15}$.

Climate change implications for krill dynamics and management. Climate change impacts on the krill population are not explicitly included in krill fisheries management, where catch limits do not change from year to year ${ }^{82}$. However, given the farreaching implications of any possible climate change-related declines in krill stocks for the Antarctic marine ecosystem, there is a need to incorporate environmental variability into the management framework explicitly by, for example, adjusting catch limits based on environmental predictors or in response to variations in stock size as is common practice in other fisheries ${ }^{82}$.

Recent field investigations of environmental changes ${ }^{83}$ and studies investigating the long-term trends in environmental variables such as water temperature, sea-ice and water-column production, and climate indices such as ENSO and the SAM, suggest they will negatively impact krill ${ }^{33,37,84}$. Importantly, projections of environmental variables that are correlated with recruitment ${ }^{38,85,86}$ suggest that climate change is likely to have a negative impact on future recruitment. Other studies suggest that there has been a long-term southward contraction of krill distribution in the SW Atlantic sector, with populations becoming concentrated toward the Antarctic continental shelves $^{38,87}$ as a consequence of climatic-driven ecosystem changes. Whether or not krill will track their thermal niche southward is complicated because of the interaction with other habitat requirements that are important for krill, including water depth, ice regimes, and quantity of primary production ${ }^{88}$. Models of krill habitat under projected future changes in ocean temperature (increase), sea ice (decrease) and chlorophyll- $a$ concentration (decrease) under the business-as-usual emission scenario could result in an $80 \%$ contraction of the available krill spawning habitat, with a complete disappearance of spawning grounds along the WAP by $2100^{89-91}$. While time-series analyses of recruitment, distribution patterns, or future projections from models have revealed population-level responses to particular climate indices $33,37,86$, the mechanisms underlying these responses are unclear.

Despite 90 years of krill research, we have only limited knowledge of the adaptive capability of krill to a range of environmental factors including temperature and ocean $\mathrm{pH}$. Field investigations have demonstrated that growth rates of adult krill from the Scotia Sea decline at sea water temperatures even a couple of ${ }^{\circ} \mathrm{C}$ above the temperature optimum ${ }^{92}$, and laboratory experiments show that early larval stages seem to be most affected by increasing $\mathrm{pCO}_{2}$ and temperature ${ }^{93}$. Increasing our efforts toward a mechanistic understanding of responses by krill to climate change and the incorporation of these data into krill population models will enable more robust projection of krill stock dynamics in the future.

\section{Future directions}

Our synthesis of present knowledge on E. superba highlights key actions that future research can take to provide a better understanding of potential future change in the krill stock (Box 2): 


\section{Box 2 | Priorities for krill research to support ecosystem-based management of the krill fishery}

Unravel the controls on krill recruitment: The recruitment term is central to population models used by fishery managers. Correlation and model studies have suggested which environmental conditions and krill behaviors favor recruitment. However, surveyed numbers of juvenile krill are far below those required to explain the patterns in abundance of adults.

Recommendations: Use continuous plankton recorders (CPR) ${ }^{95}$ and ferry boxes ${ }^{96}$ on year-round operating fishing vessels to estimate the abundance and distribution of juvenile krill and to estimate food availability, respectively. These data, added to efforts to rescue and compile existing krill data, will build the long spatial-temporal time series essential to understand the crucial early life stage. Instrument krill-dependent predators with CTD/ fluorescence sensors and echosounders (seals) ${ }^{104}$ to obtain information on environmental conditions and the depth location of krill during winter and in coastal regions, where it is difficult to access data with conventional sampling methods. Combine these efforts with remote sensing information on sea ice and new ocean color products, to reveal the physical environmental factors, driving krill recruitment.

Resolve the debate over whether krill populations have declined: Krill fishery management does not explicitly factor in the effects of long-term warming of the SW Atlantic sector and projected adverse consequences for krill. Recent debate around estimates of krill population trends has led to a lack of clarity for all stakeholders. Understanding whether krill have been impacted by, or are resilient to, the known ecosystem changes in the last 90 years is necessary to inform future projections. Addressing this issue will identify knowledge gaps and direct research efforts.

Recommendations: Workshop-based dialogue among krill researchers on what the various time series methods and models tell us about change in the krill-based food web. This is needed to provide a clear synthesis of diverging opinions on krill trends in the context of differences, for example, in time series length and location, and indices based on biomass, abundance, population structure or predators. Moving forward, the scientific community needs to provide expert opinion on how modern krill sampling methods, such as moored echosounders, gliders and the fishery itself, inform us about trends and harmonize the needs of science and spatially-resolved fisheries management.

Pinpoint the hotspots of successful spawning which merit conservation status: Studies show that successful spawning occurs primarily near shelf/ slope areas during summer, and this is reflected in subsequent larval distributions, which implies that a relatively small portion of the adult population contribute to the next generation. Given that the fishery is now concentrated on the shelf during autumn and winter, it may mean that fishing pressure on the spawning portion of the population is higher than previously thought.

Recommendations: Pursue a holistic analysis of krill maturity stage data from the fishery (collected by observers), land-based krill predators and scientific research cruises. Krill-dependent predators (seals, penguins) attached with depth sensors and GPS instruments as well as cameras and accelerometers $104-106$, along with stomach content analyses, can provide information on the location of mature krill females. Data focused on resolving where and when spawning hotspots occur can be used to assess the fishery risk to the krill stock

Identify seasonal overlaps between the fishery and successful spawning stock: Adult krill distribution shifts from mainly off-shelf in summer to onshelf in winter, where the present-day fishery effort is focused. However, the timing of this migration and the mechanisms behind it, e.g. a direct response to predation or an innate life-cycle trait, are unclear. Understanding the mechanism of this behavior and what portions of the population are involved, are critical to understanding the impact of the on-shelf fishing on this winter krill population. Critically, shelf/slope krill may represent a larger percentage of adults that will contribute to the next generation. Therefore, interim catch limits especially in Subarea 48.1, may not be as precautionary as intended (see Box 1).

Recommendations: Workshop-based dialogue among krill researchers, funding agencies and fishing industry to coordinate existing research and sampling platforms by national programs and fishing industry to enable year-round operations of acoustic equipment on moorings ${ }^{97}$ and gliders ${ }^{98}$ to estimate the biomass and migration of krill between regions and seasons, and use fishery derived demographics of the krill catch to understand what part of the population is removed by fishing.

Future-proof fishery management for climate change: Model projections suggest future reductions in conditions that are favorable to krill, and contractions of suitable habitat. This work has highlighted the need to understand the mechanisms behind krill's plasticity within its environment. In particular we need to ensure that catch limits remain appropriate even in years of climatic extremes or step-changes, since these are projected to increase.

Recommendations: Coordinated process studies on the plasticity of krill to changes in temperature, food, and carbon dioxide levels to get a mechanistic understanding between krill biology/behavior and their key habitat features (sea ice, ocean current, ocean floor topography), This will need to be combined with analyses of the developing time-series described above, to inform robust population projection models.

- Unravel the controls on krill recruitment.

- Resolve the debate over whether krill populations have declined.

- Pinpoint the hotspots of successful spawning which merit protection.

- Identify seasonal overlaps between the fishery and the contributing spawning stock.

- Future-proof fishery management for climate change.

Although krill is one of the most studied pelagic species, the gaps in the present knowledge are major. Over the past 30 years, considerable efforts have been made in the field and laboratory to understand the biology and ecology of krill through a series of scientific studies. During that time, the general conception of krill biology and its life history has changed dramatically. Years of data have been amassed, including annual acoustic data, net-based population density and demographic data, data from predator diets, and data from process studies in different seasons and locations in the SW Atlantic sector. However, there remains much debate and controversy on population trends, overwintering, migration and other key aspects of krill biology.
The main obstacle to a better understanding of krill biology lies in the difficulties associated with the logistics, operation, and planning of scientific studies. The majority of krill surveys have been conducted during the summer months, but recent investigations outside that time window have shown that studies in the other seasons are essential to understand the biology and ecology of krill, as well as their function in the Antarctic ecosystem. Examples include the on-shore migration of a large part of the population in winter ${ }^{53}$, and the overwintering diets of early life stages $^{29}$. Ship-based net and acoustic surveys have been the main contributor to our knowledge of the population dynamics of krill, and time-series analyses of these data have revealed various trends in the population. Multi-ship, large scale krill biomass surveys provide the baseline biomass estimates for krill management and require large planning effort, often over years, resulting in a single biomass estimate specific to one season. The critical point here is that these surveys are unable to give answers about population trends or why they occur. At the same time, modern fisheries, which operate almost year-round and are more concentrated than ever before in the SW Atlantic sector, are 
expanding by using new, more efficient technologies to find krill (horizontal sonars) and catch them (continuous pumping systems) ${ }^{94}$. Vessels with newer technology now harvest $80 \%$ of the krill caught in the SW Atlantic sector. These changes in catch techniques require new ways of thinking about the impact of the commercial krill fishery and the effort-based indices needed to manage krill populations.

In order to increase our knowledge of krill, we must go beyond correlative studies toward a mechanistic understanding of their life history. Combining biomass surveys with process-oriented studies, at different times of the year, either on vessels or at Antarctic field stations should continue. However, research vessel time is becoming increasingly difficult to obtain, and field stations that can be used to understand the details of the biology of krill are limited due to logistical and facility constraints of catching and maintaining krill for experimental studies. It is, therefore, crucial that we begin to coordinate international research efforts and resources. The new generations of fishing vessels and their potential year-round operation could provide new opportunities to fill the gaps in knowledge that have been identified. Cooperative research with the commercial fishery might release national scientific research vessel time to conduct studies in other areas that are potentially important for krill, and yet are not sampled sufficiently to understand their importance to krill life history in the SO.

For example, the fishery routinely takes samples from krill aggregations multiple times each day. Such data provide vital information over long periods of time on the demography of krill in different seasons and regions. These demographic data could help quantify the impact of the fishery on the krill winter population and the potential level of spawning in the coming spring. In addition, commercial vessels could provide highresolution seasonal krill sampling for studies on the physiological adaptability of krill to environmental changes. Ship acoustic systems, on fishing and research vessels, that record krill behavior patterns on small scales, could be combined with acoustic biomass data from gliders operating on larger scales to better understand the mechanism of seasonal changes in krill biomass and distribution.

In addition, autonomous sampling instruments installed on the fishing vessels, such as the continuous plankton recorder (CPR $)^{95}$ can provide the distribution pattern of juvenile krill. Installed FerryBoxes ${ }^{96}$, collecting basic environmental data, such as water temperature, salinity, primary production in terms of chlorophyll-a concentration and particulate organic carbon could provide information continuously on food availability and thus survival potential of larval krill in autumn and winter. Moorings ${ }^{97}$, gliders ${ }^{98}$, and sail buoys ${ }^{99}$ can be used to gather regular biomass data at small scales in different regions. These operations can also be carried out in close cooperation with the krill fishery that might support the deployment and recovery of these instruments.

These new efforts could provide the improved understanding of krill biology and ecology necessary to manage krill at appropriate time and space scales and can be summarized as four key activities:

- Utilizing the fishery as a scientific platform.

- Increasing laboratory capacity on Antarctic stations to conduct krill process studies in the field.

- Expanding autonomous tools and building research networks to collect and analyze these data.

- Focusing scientific research surveys on krill biology in areas and times where the fishery is absent, and where autonomous instruments cannot operate.
Such a combined effort by the krill research community and fishery would provide the opportunity to integrate the generated data into novel models that consider both individual krill and their predators in their biological and physical environment, enabling a holistic approach to ecosystem change. Furthermore, this effort would enable ecosystem-based management of the krill fishery, as a component of CCAMLR's overarching goal: the conservation of the Antarctic ecosystem as a whole.

\section{Data availability}

The data sets we used are all fully cited in the appropriate sections.

Received: 24 May 2020; Accepted: 14 September 2020; Published online: 15 October 2020

\section{References}

1. Trathan, P. N. \& Hill, S. L. in Biology and Ecology of Antarctic krill (ed. Siegel, V.) 321-350 (Springer, 2016).

2. Atkinson, A. et al. A re-appraisal of the total biomass and annual production of Antarctic krill. Deep Sea Res. Pt. 1. 56, 727-740 (2009).

3. Bar-On, Y. N., Philips, R. \& Milo, R. The biomass distribution on Earth. Proc. Natl Acad. Sci. USA 115, 6506-6511 (2018).

4. Atkinson, A. et al. Sardine cycles, krill declines, and locust plagues: revisiting 'wasp-waist' food webs. Trends Ecol. Evol. 29, 309-316 (2014).

5. Cavan, E. L. et al. The importance of Antarctic krill in biogeochemical cycles. Nat. Commun. 10, 4742 (2019).

6. Nicol, S. et al. Southern Ocean iron fertilization by baleen whales and Antarctic krill. Fish. Fish 11, 203-209 (2010).

7. Schmidt, K. et al. Zooplankton gut passage mobilizes lithogenic iron for ocean productivity. Curr. Biol. 26, 2667-2673 (2016)

8. Nicol, S. \& Foster, J. in Biology and Ecology of Antarctic krill 387-421 (Springer, 2016).

9. Kawaguchi, S \& Nicol, S. in Fisheries and Aquaculture Vol. 9. (eds Lovrich, G. \& Thiel, M.) 137-158, https://doi.org/10.1093/oso/9780190865627.003.0006. (Oxford University Press, 2020).

10. Turner, J. \& Overland, J. Contrasting climate change in the two polar regions. Polar Res. 26, 146-164 (2009).

11. Rogers, A. D. et al. Antarctic futures: an assessment of climate-driven changes in ecosystem structure, function, and service provisioning in the southern ocean. Annul Rev. Mar. Sci 12, 87-120 (2019).

12. Kawaguchi, S., Nicol, S. \& Press, A. J. Direct effects of climate change on the Antarctic krill fishery. Fisheries Manag. Ecol. 16, 424-427 (2009).

13. Trathan, P. N. et al. Krill biomass in the Atlantic. Nature 367, 201-202 (1995).

14. Constable, A. J. \& de la Mare, W. K. A generalised yield model for evaluating the yield and the long-term status of fish stocks under conditions of uncertainty. CCAMLR Sci. 3, 31-54 (1996).

15. Hill, S. L. et al. Is current management of the Antarctic krill fishery in the Atlantic sector of the Southern Ocean precautionary? CCAMLR Sci. 23, 31-51 (2016).

16. Hewitt, R. P. et al. Options for allocating the precautionary catch limit of krill among small-scale management units in the Scotia Sea. CCAMLR Sci 11, 81-97 (2004).

17. Watters, G. M., Hill, S. L., Hinke, J. T., Matthews, J. \& Reid, K. Decisionmaking for ecosystem-based management: evaluating options for a krill fishery with an ecosystem dynamics model. Ecol. Appl. 23, 710-725 (2013).

18. Trathan, P. N. et al. Managing fishery development in sensitive ecosystems: identifying penguin habitat use to direct management in Antarctica. Ecosphere 9, e02392 (2018).

19. Watters, G. M., Hinke, J. T. \& Reiss, C. Long-term observations from Antarctica demonstrate that mismatched scales of fisheries management and predator-prey interaction lead to erroneous conclusions about precaution. Sci. Rep. 10, 2314 (2020).

20. Reiss, C. S., Cossio, A. M., Loeb, V. \& Demer, D. A. Variations in the biomass of Antarctic krill (Euphausia superba) around the South Shetland Islands, 1996-2006. ICES J. Mar. Sci. 65, 497-508 (2008).

21. Fielding, S. et al. Interannual variability in Antarctic krill (Euphausia superba) density at South Georgia, Southern Ocean: 1997-2013. ICES J. Mar. Sci. 71, 2578-2588 (2014).

22. Brierley, A. S. \& Reid, K. Krill and the diversity of science and society: An introduction to the Third International Symposium on Krill. J. Crust. Biol. 38, 651-655 (2018). 
23. Report of the Thirty-Sixth Meeting of the Scientific Committee of the Commission for the Conservation of Antarctic Marine Living Resources. (CCAMLR, Hobart, Australia, 2017).

24. SC-CCAMLR Report of the thirty-eight Meeting of the Scientific Committee, of the Commission for the Conservation of Antarctic Marine Living Resources. (CCAMLR Hobart, Australia, 2019).

25. Spiridonov, V. Spatial and temporal variability in reproductive timing of Antarctic krill (Euphausia superba Dana). Polar Biol. 15, 161-174 (1995).

26. Siegel, V. Distribution and population dynamics of Euphausia superba: summary of recent findings. Polar Biol. 29, 1-22 (2005).

27. Schmidt, K., Atkinson, A., Venables, H. \& Pond, D. W. Early spawning of Antarctic krill in the Scotia Sea is fueled by 'superfluous' feeding on non-ice associated phytoplankton blooms. Deep Sea Res. II 59, 159-172 (2012).

28. Ross, R. B. \& Quetin, L. B. Energetic cost to develop to the first feeding stage of Euphausia superba Dana and the effect of delays in food availability. J. Exp. Mar. Biol. Ecol. 133, 103-127 (1989).

29. Meyer, B. et al. The winter pack-ice zone provides a sheltered but food-poor habitat for larval Antarctic krill. Nat. Ecol. Evol 1, 1853-1861 (2017).

30. Brierley, A. S., Demer, D. A., Hewitt, R. P. \& Watkins, J. L. Concordance of inter-annual fluctuations in densities of krill around South Georgia and Elephant Islands: biological evidence of same year teleconnections across the Scotia Sea. Mar. Biol. 134, 675-681 (1999).

31. Reiss, C. S. in Biology and Ecology of Antarctic krill 101-144 (Springer, 2016).

32. Quetin, L. B., Ross, R. M., Fritsen, C. H. \& Vernet, M. Ecological responses of Antarctic krill to environmental variability: can we predict the future? Ant. Sci. 19, 253-266 (2007).

33. Saba, G. K. et al. Winter and spring controls on the summer food web of the coastal West Antarctic Peninsula. Nat. Commun. 5, 4318 (2014).

34. Murphy, E. J. et al. Spatial and temporal operation of the Scotia Sea ecosystem: a review of large-scale links in a krill centered food web. Phil. Trans. R. Soc. B 362, 113-148 (2007).

35. Kinzey, D. et al. Selectivity and two biomass measures in an age-based assessment of Antarctic krill (Euphausia superba). Fish. Res. 168, 72-84 (2015).

36. Siegel, V. \& Loeb, V. et al. Recruitment of Antarctic krill (Euphausia superba) and possible causes for its variability. Mar. Ecol. Prog. Ser. 123, 45-56 (1995).

37. Loeb, V. J. \& Santora, J. A. Climate variability and spatiotemporal dynamics of five Southern Ocean krill species. Prog. Oceanogr. 134, 93-122 (2015).

38. Atkinson, A. et al. Krill (Euphausia superba) distribution contracts southward during rapid regional warming. Nat. Clim. Change 9, 142-147 (2019).

39. Thorpe, S. E., Tarling, G. A. \& Murphy, E. J. Circumpolar patterns in Antarctic krill larval recruitment: an environmentally driven model. Mar. Ecol. Prog. Ser. 613, 77-96 (2019).

40. Ryabov, A. B. et al. Competition-induced starvation drives large-scale population cycles in Antarctic krill. Nat. Ecol. Evol 1, 1-8 (2017).

41. Makarov, R. R. \& Menshenina, L. L. On the distribution of euphausiid larvae in the Antarctic waters. Okeanologija Akademija Nauk SSSR. Okeanograficeskaja Komissija, Moskva 29, 825-831 (1989).

42. Perry, F. A. et al. Habitat partitioning in Antarctic krill: spawning hotspots and nursery areas. PLoS ONE 14, e0219325 (2019).

43. Siegel, V \& Watkins, J. N. in Biology and Ecology of Antarctic krill 21-100 (Springer, 2016).

44. Hofmann, E. E. \& Hüsrevoğlu, Y. S. A circumpolar modelling study of habitat control of Antarctic krill (Euphausia superba) reproductive success. Deep-Sea Res II 50, 3121-3142 (2003).

45. King, M. Fisheries Biology, Assessment and Management 341 (Fishing News Books, Blackwell Science, Oxford, 1995).

46. Rombolá, E. R. et al. Variability of euphausiid larvae densities during the 2011, 2012, and 2014 summer seasons in the Atlantic sector of the Antarctic. Polar Sci. 19, 86-93 (2019).

47. Conroy, J. A., Reiss, C. S., Gleiber, M. R. \& Steinberg, D. K. Linking Antarctic krill larval supply and recruitment along the Antarctic Peninsula. Integr. Comp. Biol. https://doi.org/10.1093/icb/icaa111 (2020).

48. Siegel, V. et al. Distribution and abundance of Antarctic krill (Euphausia superba) along the Antarctic Peninsula. Deep Sea Res. I 77, 63-74 (2013).

49. Lumpkin, R. \& Centurioni, L. Global Drifter Program quality-controlled 6hour interpolated data from ocean surface drifting buoys. NOAA National Centers for Environmental Information. Dataset. https://doi.org/10.25921/ 7ntx-z961 (2019)

50. Siegel, V. in Antarctic Ocean and Resources Variability 219-230 (Springer, 1988).

51. Trathan, P. N. et al. Spatial variability of Antarctic krill in relation to mesoscale hydrography. Mar. Ecol. Prog. Ser. 98, 61-71 (1993).

52. Jazdzewski, K. et al. Biological and populational studies on krill near South Shetland Islands, Scotia Sea and South Georgia in the summer 1976. Polskie Archiwum Hydrobiologii 25, 607-631 (1978).

53. Reiss, C. S. et al. Overwinter habitat selection by Antarctic krill under varying sea-ice conditions: implications for top predators and fishery management. Mar. Ecol. Prog. Ser. 568, 1-16 (2017).
54. Piñones, A. et al. Modeling the remote and local connectivity of Antarctic krill populations along the western Antarctic Peninsula. Mar. Ecol. Prog. Ser. 481, 69-92 (2013)

55. Taki, K., Hayashi, T. \& Naganobu, M. Characteristics of seasonal variation in diurnal vertical migration and aggregation of Antarctic krill (Euphausia superba) in the Scotia Sea, using Japanese fishery data. CCAMLR Sci. 12, 163-172 (2005).

56. Barlow, K. E. et al. Are penguins and seals in competition for Antarctic krill at South Georgia? Mar. Biol. 140, 205-213 (2002).

57. Reid, K., Trathan, P. N., Croxall, J. P. \& Hill, H. J. Krill caught by predators and nets: differences between species and techniques. Mar. Ecol. Prog. Ser. 140, 13-20 (1996)

58. Jackson, J. A. et al. Global diversity and oceanic divergence of humpback whales (Megaptera novaeangliae). Proc. Roy. Soc. B-Biol. Sci 281, 20133222 (2014).

59. Herr, H. et al. Horizontal niche partitioning of humpback and fin whales around the West Antarctic Peninsula: evidence from a concurrent whale and krill survey. Polar Biol. 39, 799-818 (2016).

60. Viquerat, S. \& Herr, H. Mid-summer abundance estimates of fin whales Balaenoptera physalus around the South Orkney Islands and Elephant Island. ESR 32, 515-524 (2017).

61. Zerbini, A. N. et al. Assessing the recovery of an Antarctic predator form historical exploitation. Roy. Soc. Open Sci 6, 190368 (2019).

62. Reid, K. et al. Widening the net: spatio-temporal variability in the krill population structure across the Scotia Sea. Deep-Sea Res. II 51, 1275-1287 (2004).

63. Atkinson, A. et al. Oceanic circumpolar habitats of Antarctic krill. Mar. Ecol. Prog. Ser. 362, 1-23 (2008).

64. Hill, S. L., Trathan, P. H. \& Agnew, D. J. The risk to fishery performance associated with spatially resolved management of Antarctic krill (Euphausia superba) harvesting. ICES J. Mar. Sci 66, 2148-2154 (2009).

65. Tarling, G. A., Ward, P. \& Thorpe, S. E. Spatial distributions of Southern Ocean mesozooplankton communities have been resilient to long-term surface warming. Global Change Biol. https://doi.org/10.1111/gcb.13834 (2017).

66. Stammerjohn, S. S., Massom, R. A., Rind, D. \& Martinson, D. G. Regions of rapid sea ice change: an inter-hemispheric seasonal comparison. Geophys. Res. Lett. 39, L06501 (2012).

67. Henley, S. F. et al. Variability and change in the west Antarctic Peninsula marine system: research priorities and opportunities. Prog. Oceanogr. https:// doi.org/10.1016/j.pocean.2019.03.003 (2019).

68. Turner, J. et al. Absence of 21st century warming on Antarctic Peninsula consistent with natural variability. Nature. 535, 411-415 (2016).

69. Swart, N. C. \& Fyfe, J. C. Observed and simulated changes in the Southern Hemisphere surface westerly wind-stress. Geophys. Res. Letters 39, L16711 (2012).

70. Datwyler, C. et al. Teleconnection stationality, variability and trends of the Southern Annular Mode (SAM) during the last millennium. Clim. Dyn. 51, 2321-2339 (2017).

71. Stammerjohn, S. E. et al. Trends in Antarctic annual sea ice retreat and advance and their relation to El Niño-Southern Oscillation and Southern Annular Mode variability. J. Geophys. Res. 113, C03S90 (2008).

72. SC-CCAMLR Report of the twenty-ninth Meeting of the Scientific Committee, of the Commission for the Conservation of Antarctic Marine Living Resources. (CCAMLR Hobart, Australia, 2010).

73. Cox, M. J. et al. No evidence for a decline in the density of Antarctic krill Euphausia superba Dana, 1850, in the Southwest Atlantic sector between 1976 and 2016. J. Crust. Biol. 38, 656-661 (2018).

74. Loeb, V. et al. Effects of sea ice extent and krill or salp dominance on the Antarctic food web. Nature 387, 897-900 (1997).

75. Trivelpiece, W. Z. et al. Variability in krill biomass links harvesting and climate warming to penguin population changes in Antarctica. Proc. Natl Acad. Sci. USA 108, 7625-7628 (2011).

76. Huang, T. et al. Relative changes in krill abundanceiInferred from Antarctic Fur Seal. PLoS ONE 6, e27331 (2011).

77. Atkinson, A., Siegel, V., Pakhomov, E. A. \& Rothery, P. Long term decline in krill stock and increase in salps within the Southern Ocean. Nature 432, 100-103 (2004).

78. Forcada, J. \& Hoffman, J. I. Climate change selects for heterozygosity in a declining fur seal population. Nature 511, 462-465 (2014).

79. McMahon, K. W. et al. Divergent trophic responses of sympatric penguin species to historic anthropogenic exploitation and recent climate change. Proc. Natl Acad Sci. USA 116, 25721-25727 (2019).

80. Hill, S. L., Atkinson, A., Pakhomov, E. A. \& Siegel, V. Evidence for a decline in the population density of Antarctic krill Euphausia superba Dana 1850, still stands: A comment on Cox et al. J. Crust. Biol 39, 316-322 (2019). 
81. Cox, M. J. et al. Clarifying trends in the density of Antarctic krill Euphausia superba Dana, 1850 in the South Atlantic. A response to Hill et al. J. Crust. Biol. 39, 323-327 (2019).

82. Hill, S. L. et al. Reference points for predators will progress ecosystem-based management of fisheries. Fish. Fish. 21, 368-378 (2020).

83. Fuentes, V. et al. Glacial melting: an overlooked threat to Antarctic krill. Sci. Reps 6, 27234 (2016).

84. Flores et al. The response of Antarctic krill to climate change: Implications for management and research priorities. Mar. Ecol. Prog. Ser. 458, 1-19 (2012).

85. Ross, R. M. et al. Palmer LTER: Patterns of distribution of five dominant zooplankton species in the epipelagic zone west of the Antarctic Peninsula, 1993-2004. Deep Sea Res. II 55, 2086-2105 (2008).

86. Loeb, V. J. et al. ENSO and variability of the Antarctic Peninsula pelagic marine ecosystem. Ant. Sci. 21, 135-148 (2009).

87. Beaugrand, G. \& Kirby, R. R. How do marine pelagic species respond to climate change? Theories and observations. Annu. Rev. Mar. Sci. 10, 169-197 (2018).

88. Tarling, G. A. \& Thorpe, S. E. Oceanic swarms of Antarctic krill perform satiation sinking. Proc. R. Soc. B 284, 20172015 (2017).

89. Hill, S. L., Phillips, T. \& Atkinson, A. Potential climate change effects on the habitat of Antarctic krill in the Weddell Quadrant of the Southern Ocean. PLoS ONE 8, e72246 (2013).

90. Piñones, A. \& Fedorov, A. V. Projected changes of Antarctic krill habitat by the end of the $21^{\text {st }}$ century. Geophys. Res. Lett. 43, 8580-8589 (2016).

91. Murphy, E. J. et al. Restricted regions of enhanced growth of Antarctic krill in the circumpolar Southern Ocean. Sci. Reps 7, 6963 (2017).

92. Atkinson, A. et al. Natural growth rates in Antarctic krill (Euphausia superba): II. Predictive models based on food, temperature, body length, sex, and maturity stage. Limnol. Oceanogr. 51, 973-987 (2006).

93. Kawaguchi, S. et al. Risk maps for Antarctic krill under projected Southern Ocean acidification. Nat. Clim. Change 3, 343-347 (2013).

94. Kawaguchi, S. \& Nicol, S. Learning about Antarctic krill from the fishery. Ant. Sci. 19, 219-230 (2007).

95. Warner, A. J., Hays, G. C. \& Hays, G. Sampling by the Continuous Plankton Recorder survey. Prog. Oceanogr. 34, 237-256 (1994).

96. Petersen, W. FerryBox systems: State-of-the-art in Europe and future development. J. Mar. Syst. 140 A, 4-12 (2014).

97. Brierley, A. S. et al. Use of moored acoustic instruments to measure shortterm variability in abundance of Antarctic krill. Limnol. Oceanogr.: Methods 4, 18-29 (2006)

98. Guihen, D. et al. An assessment of the use of ocean gliders to undertake acoustic measurements of zooplankton: the distribution and density of Antarctic krill (Euphausia superba) in the Weddell Sea. Limnol. Oceanogr.: Methods 12, 373-389 (2014).

99. Meinig, C. et al. Public private partnerships to advance regional ocean observing capabilities: A Saildrone and NOAA-PMEL case study and future considerations to expand to global scale observing. Front. Mar. Sci. 6, 448 (2019).

100. Park, Y. H. \& Durand, I. Altimetry-derived Antarctic circumpolar current fronts. SEANOE. https://doi.org/10.17882/59800 (2019).

101. Park, Y.-H. et al. Observations of the Antarctic Circumpolar Current over the Udintsev Fracture Zone, the narrowest choke point in the Southern Ocean. J. Geophys. Res.: Oceans. 124 https://doi.org/10.1029/2019JC015024 (2019)

102. Ikeda, T. Development of the larvae of the Antarctic krill (Euphausia superba Dana) observed in the laboratory. J. Exp. Mar. Biol. Ecol. 75, 107-117 (1984).

103. Tarling, G. A. et al. Growth and shrinkage in Antarctic krill Euphausia superba is sex-dependent. Mar. Ecol. Prog. Ser. 547, 61-78 (2016).

104. Guinet, C. et al. Calibration procedures and first dataset of Southern Ocean chlorophyll $a$ profiles collected by elephant seals equipped with a newly developed CTD-fluorescence tags. Earth Syst. Sci. Data 5, 15-29 (2013).
105. Thiebot, J-B et al. Jellyfish and other gelata as food for four penguin speciesinsights from predator-borne videos. Front. Ecol. Environ. https://doi.org/ 10.1002/fee.1529 (2017).

106. Watanabe, Y. Y. \& Takahashi, A. Linking animal-borne video to accelerometers reveals prey capture variability. Proc Natl Acad. Sci. USA 10, 2199-2204 (2013).

\section{Acknowledgements}

This publication and the scientific position of R.D. was supported by a grant awarded to B. M. from the Federal Ministry of Food and Agriculture (BMEL, Project KrillBIS II, grant number 2819HS001) and contribute to the Helmholtz Research Program "Changing Earth-Sustaining our future" of the research field Earth and Environment of the Helmholtz Association, Topic 6, Suptopic 6.1. G.Z. was supported partly by the National Science Foundation of China (NSFC, grant number 41776185) and the National Key R\&D Program of China (NKRDPC, grant number 2018YFC1406801). S.L.H., G.A.T., S.E.T., and P.N.T. were supported by the Natural Environment Research Council (NERC) funding to the Ecosystems programme at the British Antarctic Survey. A.A. was supported by NERC through its 'Climate Linked Atlantic Sector Science' (NE/R015953/1). A.A. and S.L.H. received additional support from WWF. S.K. was supported by Australian Antarctic Science Program number 4512. We are grateful to Keith Reid (CCAMLR Secretariat and co-convener of the Third International Symposium on Krill), for his support on establishing SKAG and helpful comments on an earlier version of this manuscript. We thank participants at the Third International Symposium on Krill for wide-ranging discussions that helped catalyze this paper.

\section{Author contributions}

B.M. conceived the paper and lead the writing and figure design. B.M., A.A, K.S.B., A.S.B., R.D., S.L.H., E.M., D.M, F.A.P., C.S.R., E.R., G.A.T., S.E.T., P.N.T., G.P.Z., and S.K. contributed to the writing of the paper, with major contributions from A.A., S.L.H., C.S.R., B.M., and R.D. Figs $1-4$ were created by D.M. and F.A.P., and S.E.T, Fig. 5 by K.S.B. and G.A.T. and Figure Box 1 by S.L.H.

\section{Competing interests}

The authors state no competing interests.

\section{Additional information}

Supplementary information is available for this paper at https://doi.org/10.1038/s43247 020-00026-1.

Correspondence and requests for materials should be addressed to B.M.

Peer review information Primary handling editors: Heike Langenberg.

Reprints and permission information is available at http://www.nature.com/reprints

Publisher's note Springer Nature remains neutral with regard to jurisdictional claims in published maps and institutional affiliations.

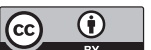

Open Access This article is licensed under a Creative Commons Attribution 4.0 International License, which permits use, sharing, adaptation, distribution and reproduction in any medium or format, as long as you give appropriate credit to the original author(s) and the source, provide a link to the Creative Commons license, and indicate if changes were made. The images or other third party material in this article are included in the article's Creative Commons license, unless indicated otherwise in a credit line to the material. If material is not included in the article's Creative Commons license and your intended use is not permitted by statutory regulation or exceeds the permitted use, you will need to obtain permission directly from the copyright holder. To view a copy of this license, visit http://creativecommons.org/ licenses/by/4.0/.

(c) The Author(s) 2020 